\title{
Penerapan Model Canvas, Marketing Mix Dan Teknologi Informasi Untuk Peningkatan Pemasaran Dan Penjualan (Pengabdian kepada Masyarakat untuk UMKM di Wilayah Cirebon)
}

\author{
*Dwi Rorin Mauludin Insana \\ Universitas Indraprasta PGRI Jakarta \\ Jl. Raya Tengah No.80 Gedong, Pasar Rebo, Jakarta Timur 13760 \\ *E-mail : dwirorin@ gmail.com \\ DOI: https://doi.org/10.21107/pangabdhi.v6i2.7586 \\ Naskah diterima 16 Juni 2020, Revisi 29 Juli 2020, Terbit 29 Oktober 2020
}

\begin{abstract}
Abstrak
Kegiatan pengabdian masyarakat ini adalah wujud nyata implementasi mata kuliah Kewirausahaan dan salah satu upaya mendukung misi pemerintah dalam rangka mencetak wirausaha baru. Implementasi ini seiring dengan kebutuhan UMKM binaan mitra tentang peningkatan penjualan dengan strategi marketing dan penyusunan biaya yang efektif sehingga memerlukan trik dan tips dalam menghadapinya. Dengan melibatkan UPTD PPMPP Cirebon yang merupakan UPTD Dinas Kelautan dan Perikanan Provinsi Jawa Barat sebagai mitra dan sebanyak 60 orang peserta yang berasal dari UMKM binaan mitra, kegiatan pengabdian masyarakat ini bertujuan diantaranya adalah sebagai berikut: 1) Meningkatkan pengetahuan, keterampilan maupun sikap atau nilai-nilai yang benar dalam mengembangkan wirausaha baru; 2) Menciptakan dan mengembangkan kemampuan usaha terutama dalam menyusun bisnis model canvas, strategi marketing mix, pemanfaatan teknologi informasi dan rencana penjualan serta penyusunan biaya agar dapat mengembangkan UMKM dan meningkatkan kesejahteraan dan ekonomi masyarakat. Metode yang digunakan dalam kegiatan ini berupa ceramah dan diskusi. Hasil dari kegiatan ini Peserta mendapatkan ilmu dan pengetahuan serta praktek tentang penyusunan model bisnis canvas, strategi marketing mix dan pemanfaatan teknologi informasi yang cukup penting dalam peningkatan penjualan dan pengembangan usahanya serta penyusunan anggaran biaya usaha
\end{abstract}

Kata Kunci : bisnis model canvas, marketing mix, teknologi informasi, pemasaran, penjualan

\begin{abstract}
This community service activity is a concrete manifestation of the implementation of the Entrepreneurship course and one of the efforts to support the government's mission in order to create new entrepreneurs. This implementation is in line with the needs of partners fostered MSMEs about increasing sales with marketing strategies and cost effective preparation that requires tricks and tips in dealing with it. By involving the UPTD PPMPP Cirebon which is the UPTD of the Office of Maritime Affairs and Fisheries of West Java Province as a partner and as many as 60 participants coming from partnered MSMEs, these community service activities aim to include the following: 1) Increase knowledge, skills and attitudes or values true values in developing new entrepreneurs; 2) Creating and developing business capabilities, especially in compiling canvas business models, marketing mix strategies, utilizing information technology and sales plans and preparing costs so that they can develop MSMEs and improve the welfare and economy of the community. The method used in this activity is in the form of lectures and discussions. The results of this activity Participants gain knowledge and knowledge as well as practice about the preparation of the business model canvas, marketing mix strategy and the use of information technology that is quite important in increasing sales and business development and preparing business budget.
\end{abstract}

Key Words: canvas model business, marketing mix, information technology, marketing, sales 


\section{PENDAHULUAN}

Permasalahan Salah satu misi Gubernur Jawa Barat adalah membangun masyarakat yang berkualitas dan berdaya saing. Peningkatan daya saing masyarakat tersebut ditempuh antara lain melalui Program Pencetakan Seratus Ribu Wirausaha Baru di Daerah Provinsi Jawa Barat. Program ini selain diharapkan dapat meningkatkan daya saing, juga diharapkan dapat meningkatkan taraf perekonomian masyarakat. Pengembangan usaha bernilai tambah dan peningkatan produktivitas suatu usaha sangat membutuhkan keberadaan dan esksistensi wirausaha baru yang berjiwa tangguh, kreatif dan profesional (Alma, 2009; Mudjiarto, 2008; Hendro, 2011; Kasmir, 2013).

Dalam rangka mendukung program Gubernur Jawa Barat tersebut, Dinas Kelautan dan Perikanan Provinsi Jawa Barat akan melaksanakan beberapa kegiatan yang bertujuan mensukseskan program sehingga lebih terarah dan sesuai target yang ditetapkan. Kegiatan sebagaimana yang tercantum dalam Peraturan Gubernur Jawa Barat Nomor : 79 Tahun 2015 tentang Pencetakan Seratus Ribu Wirausaha Baru di Daerah Provinsi Jawa Barat, dapat berupa pelatihan, pemagangan, pendampingan dan monitoring evaluasi terhadap masyarakat calon wirausaha baru.

Para calon wirausaha baru perlu diberikan pemahaman tentang penggalian ide gagasan kreatif. Hal ini sangat penting karena ide gagasan kreatif inilah yang akan memunculkan keunikan dan membedakan dengan usaha-usaha lainnya sehingga usaha yang akan dilakukan menjadi memiliki nilai tambah dan daya jual yang lebih dibandingkan yang lainnya (Carol, Kinsey Goman, 1991). Kemudian pemahaman terhadap kekuatan dan kelemahan serta peluang dan ancaman atau sering disebut SWOT Analisis perlu dilakukan oleh calon wirausahawan untuk dapat mengantisipasi permasalahan dan menyiapkan strategi dalam menjalankan usaha kedepannya (Rangkuti, 2010; David, 2011). Permasalahan yang perlu diantisipasi oleh para calon wirausahawan selanjutnya yaitu bagaimana produk yang nanti ada bisa terjual ke konsumen, sehingga sangat dibutuhkan pemahaman tentang manajemen dan strategi pemasaran dan penjualan (Kotler, 2008). Selain itu di era revolusi industry 4.0 pemahaman terhadap teknologi informasi serta pemanfaatan teknologi informasi untuk mendukung pengembangan usaha terutama untuk penjualan dan pemasaran para wirausawan sangat penting. Para wirausawan perlu diberikan pemahaman tentang penggunaan e-marketing, e-commerce serta pemanfaatan media social untuk bisa mendukung pengembangan usahanya (Chaffey et al, 2000; Rayport, Jeffrey F. dan Bernard J.Jaworski, 2003; Strauss, Judy dan Raymond Frost, 2009; Insana, DRM dan Ambar Tri Hapsari, 2019; Insana, DRM., Ambar Tri Hapsari, Eko Cahyo Mayndarto, 2019).

Beberapa hal lainnya yang perlu diketahui dan dipahami oleh para wirausahawan baru adalah bagaimana membuat peta pemikiran dan model bisnis serta penyusunan rencana usaha dan laporan keuangan. Model bisnis yang cukup mudah dibuat yaitu model bisnis canvas yang memetakan bisnis yang akan dilakukan menjadi 9 blok yaitu segmen pelanggan, manfaat atau nilai tambah, saluran distribusi, hubungan pelanggan, mitra utama, kegiatan utama, sumberdaya utama, struktur biaya dan pendapatan. Sembilan kerangka ini digunakan untuk menyederhanakan konsep model bisnis yang rumit dan kompleks agar dapat dimanfaatkan oleh sebuah perusahaan/ wirausaha untuk membuat, mendiskusikan, dan memahami sebuah model bisnis dengan lebih sistematis (Tim PPM Manajemen, 2017). Selanjutnya para wirausahawan perlu pengetahuan dan pemahaman tentang penyusunan rencana usaha dan pembuatan laporan keuangan, hal ini cukup penting untuk keberlangsungan dan kesehatan usaha yang akan dijalankan

UPTD PPMPP Cirebon merupakan UPTD Dinas Kelautan dan Perikanan Provinsi Jawa Barat yang salah satu tugas pokok dan fungsinya adalah menyelenggarakan, penerapan dan pengembangan inovasi teknologi pengolahan hasil perikanan. Terkait dengan hal tersebut UPTD PPMPP Cirebon memiliki mitra beberapa pengolah ikan sebagai masyarakat binaan yang tersebar di seluruh wilayah Jawa Barat. Namun untuk mendukung program Gubernur Jawa Barat seperti yang telah dijelaskan sebelumnya, UPTD PPMPP Cirebon juga mengadakan Kegiatan Pencetakan Wirausaha Baru yang dimulai sejak tahun 2016 dengan menyelenggarakan kegiatan Pelatihan Wirausaha Baru Bidang Pengolahan Ikan yang tersebar di wilayah Kabupaten/ Kota di Jawa Barat.

Selama tahun 2016 sampai dengan 2017 telah terselenggara Pelatihan Wirausaha Baru Bidang Pengolahan Ikan sebanyak 10 angkatan 
(5 angkatan/tahun) dan berhasil mencetak sebanyak 300 orang wirausahawan.

Pada tahun 2018, UPTD PPMPP Cirebon mengadakan kembali Kegiatan Pelatihan Wirausaha Baru Bidang Pengolahan Ikan, mengingat masyarakat binaan tersebut tidak hanya membutuhkan informasi atau pengetahuan yang terkait dengan teknis pengolahan ikan, akan tetapi juga membutuhkan informasi dan pengetahuan mengenai permodalan, kelembagaan, pemasaran dan pengembangan usahanya. Sehingga pihak UPTD PPMPP Cirebon sangat antusias menerima dan mengharapkan Tim Abdimas UNINDRA untuk bisa melaksanakan kegiatan pelatihan.

Melihat masalah tersebut di atas, kami menyadari bahwa permasalahan dan kendala yang dihadapi oleh para pengusaha UMKM lebih banyak pada strategi pemasaran yang masih kurang, permodalan dan pengelolaan keuangan, sehingga hal ini menjadi perhatian Tim Abdimas untuk bisa berbagi ilmu yang dimiliki dengan memberikan penyuluhan tentang penyusunan straegi pemasaran, memperkirakan penjualan dan pengelolaan keuangan sederhana untuk UMKM. Beberapa solusi yang dapat ditawarkan adalah (1) Pengusul memberikan pengetahuan tentang penyusunan model bisnis canvas sebagai dasar untuk menyusun strategi marketing, (2) Pengusul memberikan pengetahuan tentang marketing mix sebagai dasar dalam memperkirakan pasar dan penjualan dan pemanfaatan penggunaan teknologi informasi untuk penjualan dan pemasaran (3) Pengusul memberikan pengetahuan tentang teknik perencanaan keuangan sederhana untuk UMKM. Target dari kegiatan pengabdian masyarakat ini adalah 30 peserta dari kalangan UMKM di wilayah Cirebon dengan harapan bisa meningkatkan ; 1). Pengetahuan peserta tentang model bisnis canvas sehingga diharapkan peserta bisa menyusun rencana pemasaran dan penjualan, 2). Pengetahuan peserta tentang marketing mix dan teknologi informasi sehingga diharapkan peserta bisa menyusun strategi marketing dan penjualan, 3). Pengetahuan peserta tentang penyusunan rencana biaya dalam menjalankan usahanya.

\section{METODE}

Pemilihan mitra dalam kegiatan pengabdian masyarakat ini adalah berdasarkan kebutuhan pihak UPTD PPMPP Cirebon yang akan mengadakan kembali Kegiatan Pelatihan Wirausaha Baru Bidang Pengolahan Ikan, mengingat masyarakat binaan tersebut tidak hanya membutuhkan informasi dan pengetahuan yang terkait dengan teknis pengolahan ikan, akan tetapi juga membutuhkan informasi dan pengetahuan mengenai permodalan, kelembagaan, pemasaran dan pengembangan usahanya.

Kegiatan ini dilakukan secara bersama oleh Tim Pengabdian Masyarakat dengan mitra melalui langkah-langkah sebagai berikut.

\section{Survei}

Survei awal dilakukan oleh tim pengabdian masyarakat dengan tujuan untuk mengetahui kondisi mitra secara umum dan kebutuhan materi pengabdian masyarakat.

2. Perencanaan

Tim pengabdian masyarakat bekerjasama dengan pihak mitra menyusun perencanaan pelaksanaan pelatihan meliputi penentuan jadwal pertemuan, tempat pertemuan, agenda, tenaga pelatih dan kepanitiaan.

3. Perijinan

Tim pengabdian masyarakat melakukan perijinan kepada pihak-pihak terkait untuk memberikan pelatihan.

4. Pelaksanaan

Pemberian pelatihan dilakukan oleh tim pengabdian masyarakat. Sementara itu, pihak mitra bertugas menyediakan sarana prasarana demi lancarnya kegiatan pelatihan.

\section{Evaluasi}

Proses evaluasi dilakukan oleh pihak mitra dan tim pengabdian masyarakat di tempat kegiatan abdimas.

Untuk mencapai tujuan yang telah ditetapkan, maka kegiatan pengabdian kepada masyarakat ini dilakukan dengan menggunakan dua metode sebagai berikut.

1. Ceramah

Metode ini dilakukan dengan menyampaikan teori tentang model bisnis canvas, marketing mix dan teknologi informasi, strategi dan penyusuan anggaran biaya usaha.

2. Diskusi dan Pendampingan

Metode diskusi ini digunakan untuk lebih mendalami permasalahan dan menambah pemahaman tentang materi yang ada. Sedangkan pendampingan dilakukan pada saat praktikum dan dilanjutkan melalui konsultasi via telpon dan media sosial setelah para peserta selesai mengikuti pelatihan.

Sebelum pemberian materi peserta diberikan angket tentang biodata, usaha yang dilakukan 
dan rencana pengembangan usaha. Kegiatan ditutup dengan penyampaian angket evaluasi kegiatan.

\section{HASIL DAN PEMBAHASAN}

Secara umum pelaksanaan kegiatan pengabdian masyarakat dilaksanakan selama 3 bulan mulai bulan Maret 2018 sampai dengan bulan Mei 2018. Kegiatan pengabdian kepada masyarakat ini merupakan hasil kesepakatan antara Tim abdimas dengan mitra untuk mengatasi permasalahan yang dihadapi.

Adapun kegiatan ini dilaksanakan sebanyak 2 angkatan bertempat di Hotel Grage Sankan Kuningan Cirebon, Jawa Barat. Angkatan pertama dilaksanakan pada tanggal 28 Maret 2018 yang diikuti oleh 30 peserta pelaku UMKM yang berasal dari wilayah Kota dan Kabupaten Cirebon. Angkatan kedua dilaksanakan pada tanggal 8 Mei 2018 yang diikuti oleh 30 peserta pelaku UMKM yang berasal dari wilayah Kabupaten Indramayu dan Kabupaten Majalengka.

Selama ini masih banyak rekanan mitra binaan yang masih belum memahami visi, misi, arah dan tujuan usaha yang dilakukannya. Hal ini
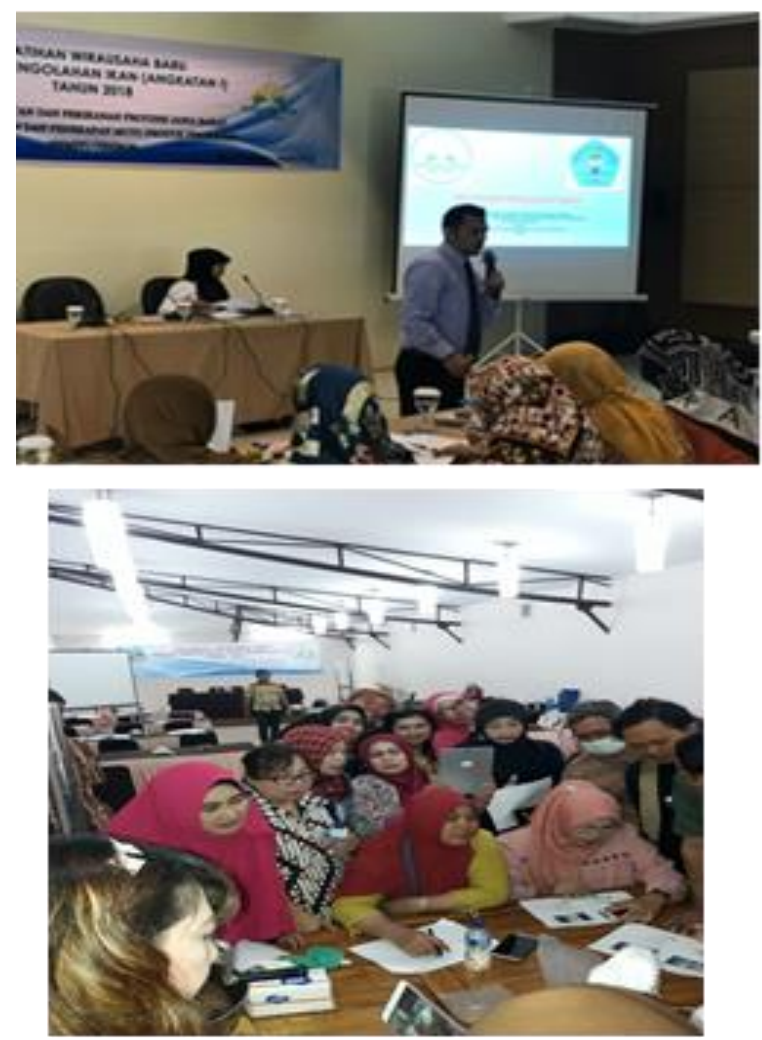

karena usaha yang dilakukan hanya bersifat seadanya atau melanjutkan usaha yang sudah berjalan. Melalui pelatihan ini para peserta mulai mengenal bagaimana menyusun model bisnis dengan model bisnis canvas. Dari situ mereka mulai memahami bisnis yang akan dilakukan kedepannya dan mempersiapkan diri untuk menghadapi tantangan yang akan datang. Selain itu mereka mulai mengenal bagaimana strategi marketing yang efektif dan efisien dengan memaksimalkan pemanfaatan teknologi informasi internet melalui penggunaan halaman facebook, instagram atau toko online dalam pengembangan usahanya. Kemudian untuk memulai menjalankan usaha mereka sudah mulai mencoba menyusun rencana anggaran biaya usaha secara sederhana.

Peserta sangat antusias dalam mengikuti pelatihan ini, karena materi yang disampaikan tergolong baru menurut mereka sehingga pada saat disampaikan materi tentang model bisnis canvas dan penggunaan teknologi informasi untuk meningkatkan pemasaran dan penjualan mereka sangat antusias dan serius mengikuti pelatihan sampai selesai. Pada saat pemberian tugas untuk pembuatan model bisnis canvas dan membuat halaman facebook, instagram dan toko
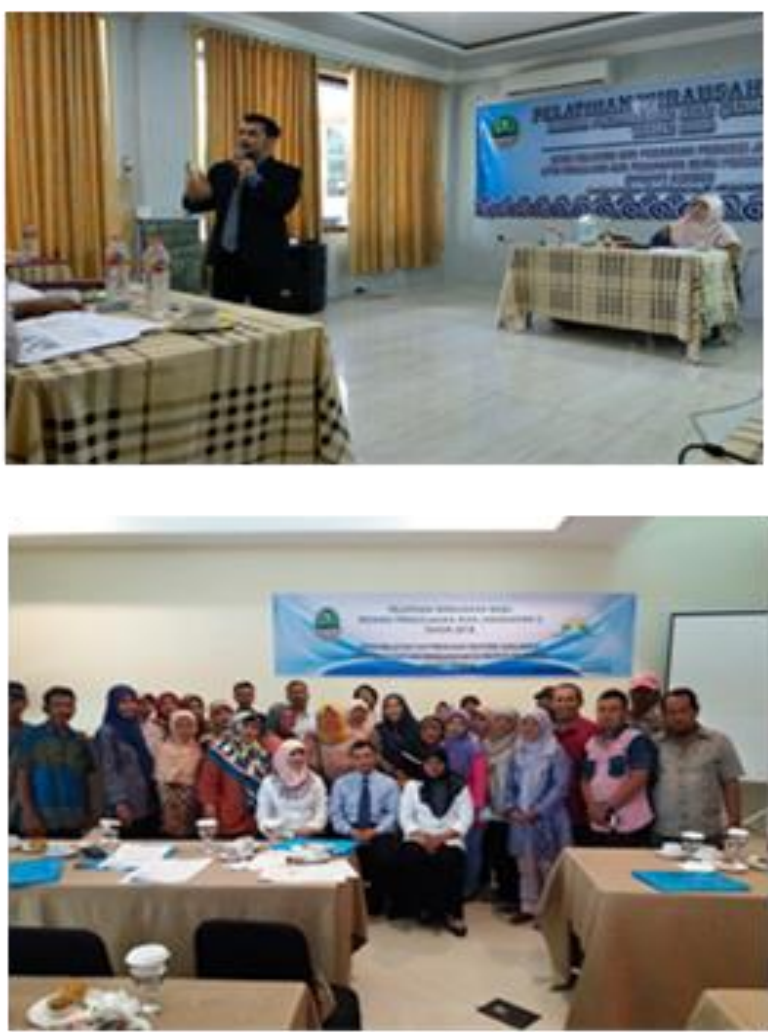

Sumber: Dwi Rorin Mauludin Insana, (2018)

Gambar 1 Foto-foto Kegiatan 
online mereka sangat antusias dengan menyelesaikan tugas dengan baik dan bersemangat pada saat diskusi kelompok. Hal yang sama juga dilakukan dalam kegiatan pengabdian masyarakat dengan pemanfaatan teknologi informasi dalam rangka meningkatkan motivasi orang untuk berwirausaha dan meningkatkan pendapatan (Insana dan Hapsari, 2019). Begitu juga dengan para pengusaha bisa memanfaatkan teknologi informasi untuk pengembangan bisnisnya terutama sebaga media promosi dan penjualan (Insana et.al, 2019)

Beberapa kendala dalam kegiatan pelatihan ini diantaranya sebagian besar peserta berasal dari kalangan UMKM yang terdiri dari ibu-ibu rumah tangga dengan pendidikan masih rendah sehingga masih banyak yang kesulitan dalam menggunakan teknologi informasi dan internet.

Secara umum pelaksanaan pelatihan berjalan sangat baik dan sesuai harapan terutama jumlah kehadiran peserta yang hampir memenuhi ruangan pelatihan yang disiapkan. Dari hasil evaluasi kegiatan melalui kuesioner, mitra dan peserta pelatihan sangat puas dengan pelaksanaan kegiatan pelatihan, dan menginginkan pelatihan ini dilakukan secara rutin dengan topik yang berbeda-beda. Pelatihan yang sangat diharapkan untuk segera dilaksanakan adalah pelatihan pengemasan produk dan merk dagang serta digital marketing.

\section{KESIMPULAN}

Berdasarkan hasil dan pembahasan, dapat diambil kesimpulan yaitu bahwa secara umum kegiatan Abdimas ini cukup berhasil dan berjalan lancar. Para peserta mendapatkan pengetahuan dasar tentang penyusunan model bisnis canvas, penyusunan strategi pemasaran menggunakan teknologi informasi, dan penyusunan rencana anggaran biaya usaha dan memahaminya serta mulai mempraktekan dengan membuat halaman facebook dan instagram serta toko online untuk mempromosikan usaha yang dimilikinya dan mencari informasi bahan baku untuk produksi.

Dari hasil evaluasi melalui angket peserta merasa materi yang disampaikan sudah sesuai kebutuhan dan sangat mudah dipahami.

Peserta diharapkan untuk langsung mempraktekan penyusunan bisnis model canvas, penyusunan strategi pemasaran, penggunaan teknologi informasi dan penyusunan anggaran biaya pada usaha yang akan atau sedang dijalankan sehingga akan lebih nyata dan sebagai bentuk implementasi teori yang sudah diterima. Kemudian perlu adanya tindak lanjut kegiatan berupa pelatihan dan pendampingan lanjutan untuk peserta sehingga hasil kegiatan pengabdian masyarakat bisa lebih terasa manfaatnya dan bisa membantu dalam meningkatkan pengembangan usaha peserta. Harapan terakhir perlu adanya peran serta pemerintah daerah setempat untuk pembinaan peserta UMKM untuk lebih mengembangkan usaha peserta.

\section{DAFTAR PUSTAKA}

Alma, B. 2009. Kewirausahaan. Bandung. Alfabeta.

Carol, K.G. 1991. Kreatifitas dalam Bisnis. Jakarta. Bina Rupa Aksara.

Chaffey, D., Mayer, R., Johnston, K \& Fiona Ellis-Chadwick. 2000. Internet Marketing: Strategy, Implementattion and Practice, Pearson Education Limited, London, England. Sumber http://lp3m.asia.ac.id/wpcontent/uploads/2017/03/7.-JURNALTHERESIA-JIBEKA-VOL-11-NO-2-FEB2017.pdf Diakses 14 Maret 2018

David, F.R. 2011. Manajemen Strategis Konsep. Jakarta. Salemba Empat.

Hendro. 2011. Dasar-dasar Kewirausahaan. Jakarta. Penerbit Erlangga.

Insana, D.R.M \& Hapsari, A.T. 2019. Peningkatan Efektivitas Berwirausaha Melalui Pemanfaatan Teknologi Informasi. Simposium Nasional Ilmiah, Kampus Universitas Indraprasta PGRI Jakarta 7 November 2019. LPPM Universitas Indraprasta PGRI, hal.1053-1059.

Insana, D.R.M., Hapsari, A.T \& Eko Cahyo M. 2019. Increasing Entrepreneurial Creativity Through the Introduction of Information Technology Utilization. Research Article in The 1st Workshop on Multimedia Education, Learning, Assessment and its Implementation in Game and Gamification. In conjunction with COMDEV 2018, Medan Indonesia, 26th January 2019, WOMELA-GG.

Kasmir. 2013. Kewirausahaan. Jakarta. Rajawali Pers.

Kotler, P. 2008. Manajemen Pemasaran (edisi ke tigabelas). Jakarta. Erlangga.

Rangkuti, F. 2010. Analisis SWOT Teknik Membedah Kasus Bisnis. Jakarta. Gramedia Pustaka Umum. 
Rayport, Jeffrey F. dan Bernard J.Jaworski. (2003). Introduction to E-Commerce, 2nd Edition, McGraw-Hill, New York Sumber http://lp3m.asia.ac.id/wpcontent/uploads/2017/03/7.-Jurnal-TheresiaJibeka-Vol-11-No-2-FEB-2017.pdf Diakses 14 Maret 2018.

Strauss, Judy dan Raymond Frost. 2009. EMarketing, 5th Edition, Prentice-Hall, Inc., Upper Saddle, New Jersey Sumber http://lp3m.asia.ac.id/wpcontent/uploads/2017/03/7.-JURNALTHERESIA-JIBEKA-VOL-11-NO-2-FEB2017.pdf Diakses 14 Maret 2018.

Tim PPM Manajemen. (2017). Business Model Canvas; Penerapan di Indonesia. Jakarta. PPM Manajemen. 